http://jmscr.igmpublication.org/home/ ISSN (e)-2347-176x ISSN (p) 2455-0450 crossref DOI: https://dx.doi.org/10.18535/jmscr/v8i3.57

\title{
Catheter Fracture: A Rare Complication of Chemotherapy Catheter Presentation of Case
}

\author{
Authors \\ Dr Sapna Patel ${ }^{1}$, Dr Darshan Thummar ${ }^{2}$ \\ ${ }^{1}$ Asst Professor, GCRI \\ ${ }^{2}$ Resident, GCRI
}

Two cases of catheter fracture are described and potential causes are discussed.

\section{Case Report 1}

$>$ A 43-year-old woman with carcinoma of the right breast had been admitted for systemic chemotherapy with cyclophosphamide, doxorubicin (CDregimen).

On September 12, 2018, a totally implantable central venous access system was implanted in the subclavian vein using the Seldinger technique with a peel-away sheath.

$>$ The postoperative chest X-ray on September 12, 2018 demonstrated normal position of CVC line. (Figure 1).

$>$ Four 3-weekly courses of chemotherapy were given.

$>$ Because no blood could be aspirated through the catheter, a chest radiograph was obtained on august 1, 2019. It showed a fracture of the silicon catheter below the clavicle with the distal portion of the catheter in the right pulmonary artery (Fig.

2)
$>$ This distal fragment was removed percutaneously through the right femoral artery.

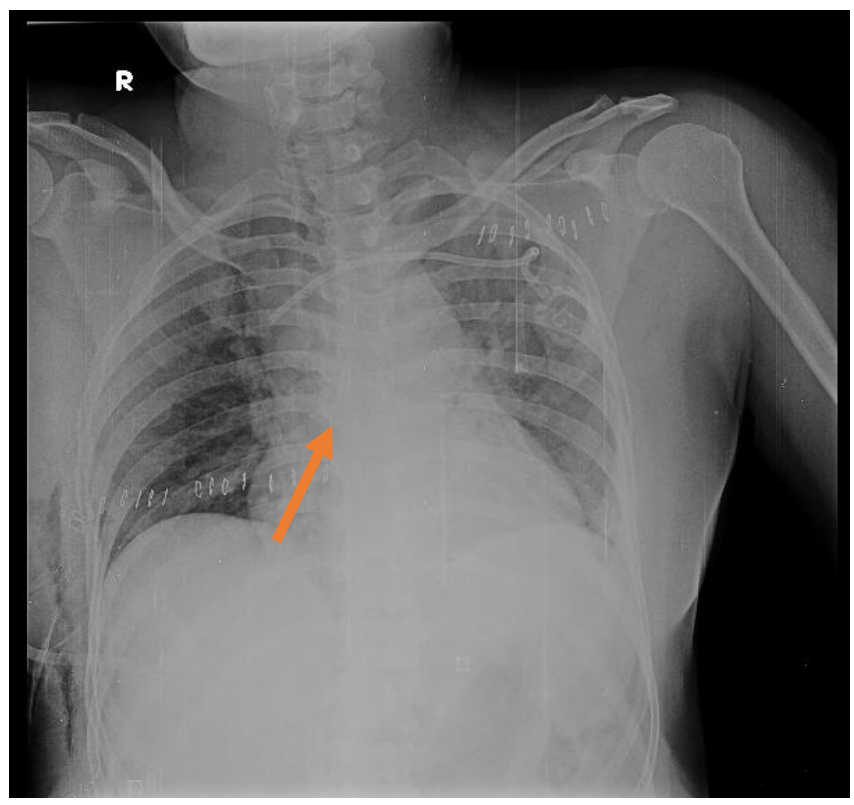

Figure 1 The postoperative chest X-ray on September 12, 2018 normal position of CVC line. 


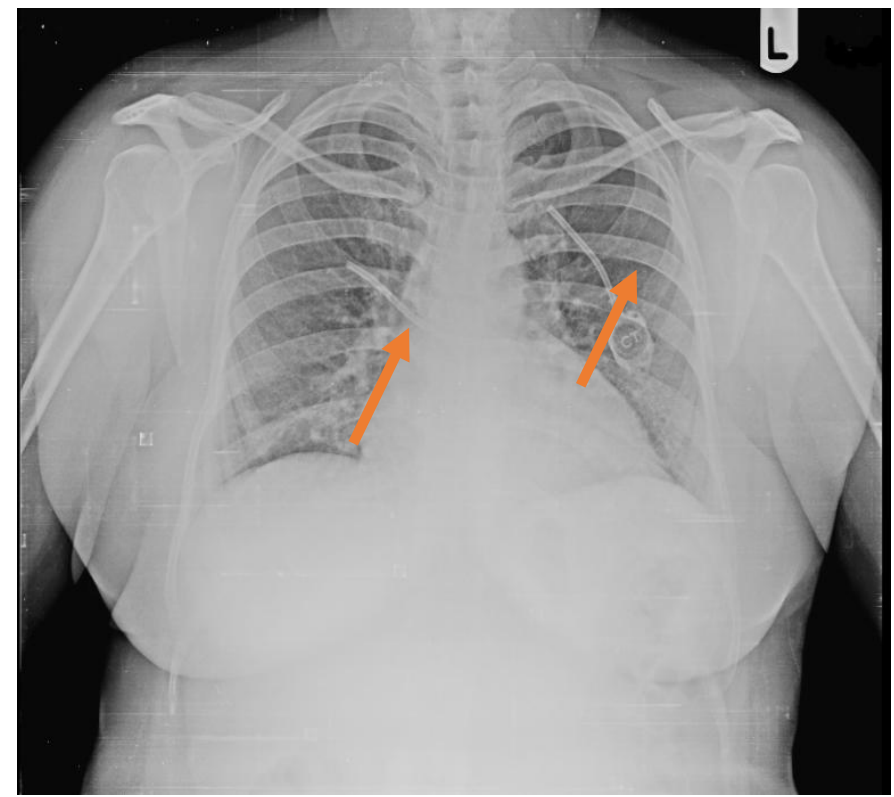

Figure 2 August 1, 2019 fracture of the silicon catheter with the distal portion of the catheter in the right pulmonary artery.

\section{Case Report 2}

$>$ A 55-year-old woman with carcinoma of the left breast had been admitted for systemic chemotherapy with cyclophosphamide, doxorubicin (CDregimen).

$>$ On October 6, 2018, a totally implantable central venous access system was implanted in the subclavian vein using the Seldinger technique with a peel-away sheath.

> The postoperative chest X-ray on October 6, 2018 demonstrated normal position of CVC line. (Figure 1).

$>1$ course of chemotherapy was given until October 25, 2018.

$>$ Because no blood could be aspirated through the catheter, a chest radiograph was obtained on November 6, 2018. It showed a fracture of the silicon catheter below the clavicle with the distal portion of the catheter in the right atrium.(Fig. 2)

$>$ This distal fragment was removed percutaneously.

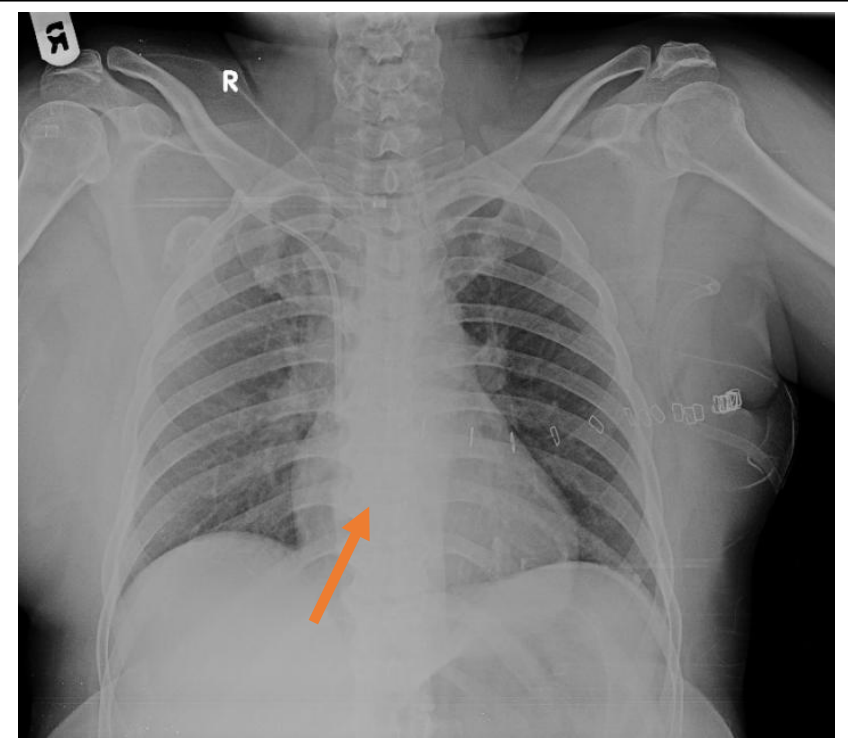

Figure 1 The postoperative chest $\mathrm{X}$-ray on October 6, 2018 normal position of CVC line.

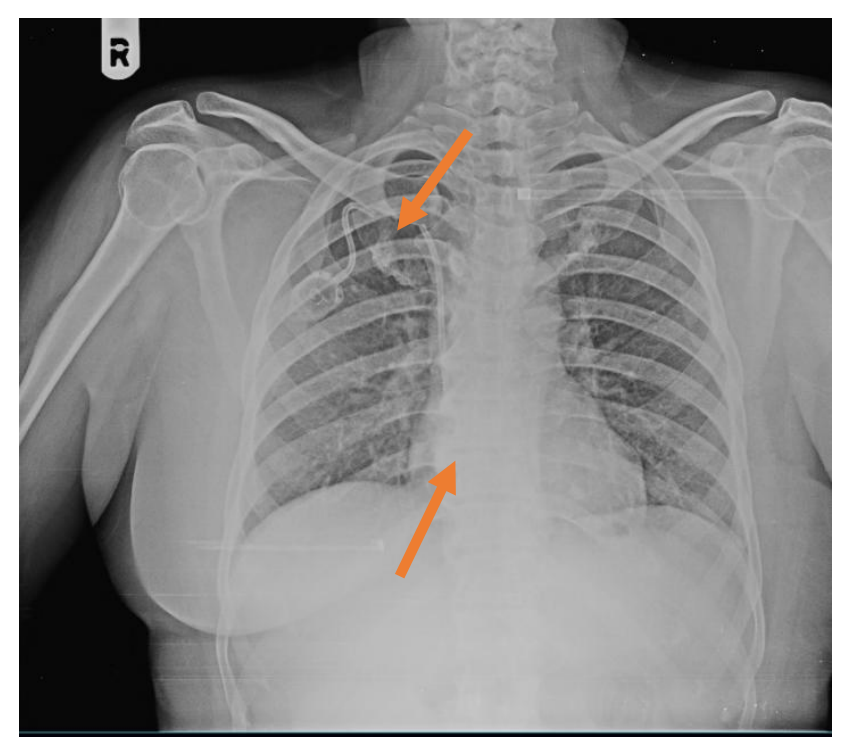

Figure 2 November 6, 2018 fracture of the silicon catheter with the distal portion of the catheter in the right atrium.

\section{Clinical Diagnosis}

As there was no blood withdrawal noted form catheter in both cases at time of chemothepy injection. They suspect catheter fracture.

\section{Differential Diagnosis}

There is no differential diagnosis in these cases. They are aunt Minnies.

\section{Discussion of Management}

$>$ Insertion of totally implantable long-term central venous access systems has become 
a routinely performed intervention for application of chemotherapeutic agents and to take blood samples during the therapy.

Long term results as well as surgical complications are well documented in the literature. These are generally approached as either immediate or delayed complications. Immediate complications are largely related to the technique at the time of insertion, manifesting as a result of injury to surrounding organs and vasculature, while delayed complications are more inherent to device malfunction and the development of infection. ${ }^{[1]}$

There is one rare complication, known as pinch-off sign, describing a compression of the catheter between clavicle and the first rib.We present two cases of catheter fracture as a consequence of the pinch-off syndrome, as well as our suggestions to prevent this complication.

> The use of the Seldinger technique with a peel-away sheath, has become a safe and rapid method to introduce a totally implantable long term central venous access system. ${ }^{[6]}$

$>$ The operative and postoperative complications are rare. Among the postoperative noninfectious complications, thrombotic occlusion of the catheter as well as mechanical complications have been described.

$>$ In 1984 Aitken and Minton $141^{[4]}$ first mentioned the so called "pinched-off sign," consisting of a narrowing of the catheter as it passes over the first rib and beneath the clavicle.

$>$ In a series of 987 patients with implantable central venous access devices placed via the subclavian vein, Hinke et al. [5] found 11 cases $(1.1 \%)$ with the pinchoff sign.

$>$ He defined a radiographic scale of catheter distortion.
$>$ Grade 0 , no distortion, catheter runs a smooth curved course in the region of the clavicle and the first rib.

$>$ Grade 1, abrupt change in direction, but no luminal narrowing.

$>$ Grade 2, some degree of luminal narrowing.

$>$ Grade 3, complete catheter fracture.

$>73 \%$ of cases were diagnosed within 3 weeks of catheter placement. Only one patient developed grade 3 pinch-off 5 weeks following catheter insertion.

$>$ Lorenz $^{[2]}$ et al. reported one pinchoff sign in a series of 57 patients, initially grade 2 , finally grade $\mathbf{3}$ at $\mathbf{3}$ months following implantation.

$>$ A retrospective study from Koonings and Given $^{[3]}$ showed an incidence of pinch-off sign in $5 \%$ of cases without any catheter fracture in a series of 100 patients.

$>$ In our first case, the scarred slun made it difficult to find the ideal site of puncture. We suspect, that in this case the puncture was in a medial position with an pinch-off sign grade 3 . In this case, the catheter fracture occurred at least 10 months after insertion

$>$ In our $2^{\text {nd }}$ case, the catheter had been inserted in a medial position too with a radiological pinch-off sign grade 3 at 4 weeks following the operative procedure.

We suggest the following precautions when introducing a totally implantable long-term central venous access system to avoid a pinch-off syndrome:

1) Penetration of the skin with the puncture needle lateral to the midclavicular line. Direct puncture of the vein without bending the needle under the clavicle.

2) In case of difficult puncture of the subclavian vein, the patient's position should not be optimized to produce a temporary widening of the clavicularfirst rib angle. 
3) If the postoperative chest radiograph shows the typical pinch-off sign, the patient should be followed carefully by chest radiograph every 4 weeks.

4) In case of the typical pinch-off sign, the catheter system should be removed within 6 months whenever possible.

Final Diagnosis: Catheter Fracture

\section{References}

1. Cassidy FP, Zajko AB, Bron KM, et al.: Non-infectious complications of long-term central venous catheters: Radiologic evaluation and management. AJR 149671675, 1987.

2. Lorenz M, Hottenrott C, Seufert RM, et al.: Long-term experience with totally subcutaneous implanted infusion chambers used as permanent central venous access. Langenbecks Arch Chir 373:302- 309, 1988.

3. Koonings PP, Given FT: Long term experience with a totally implanted catheter system in gynecologic oncologic patients. J Am Coll Surg 178:164-166, 1994.

4. Aitken DR, Minton JP: The "Pinch-off sign": Warning of impending problems with permanent subclavian catheters. Am J Surg 148:633- 636, 1984.

5. Hinke DH, Zandt-Stastny DA, Goodman LR, et al.: Pinch-off syndrome: A complication of implantable subclavian venous access devices. Radiology 177:353-356, 1990.

6. Lafreniere R: Indwelling subclavian catheters and a visit with the "pinched-off sign.” J SurgOncol 47:261-264, 1991. 